\title{
Ruminant and industrially produced trans fatty acids: health aspects
}

\author{
Steen Stender', Arne Astrup ${ }^{2}$ and Jørn Dyerberg'
}

'Department of Clinical Biochemistry, Gentofte University Hospital, Denmark; ²Department of Human Nutrition, Centre for Advanced Food Studies, Faculty of Life Sciences, The University of Copenhagen, Frederiksberg, Denmark

Abstract

Fatty acids of trans configuration in our food come from two different sources - industrially produced partially hydrogenated fat (IP-TFA) used in frying oils, margarines, spreads, and in bakery products, and ruminant fat in dairy and meat products (RP-TFA). The first source may contain up to $60 \%$ of the fatty acids in trans form compared to the content in ruminant fat which generally does not exceed $6 \%$. In Western Europe, including Scandinavia, the average daily intake of IP-TFA has decreased during the recent decade due to societal pressure and a legislative ban, whereas the intake of RP-TFA has remained stable.

In spite of this decrease we have found that in many countries consumption $>20 \mathrm{~g}$ of IP-TFA in a one-meal menu consisting of some popular foods is possible, even though the average intake of IP-TFA in these countries is low. Subgroups of the populations may therefore, on average, consume $>5 \mathrm{~g}$ IP-TFA per day. This level of consumption is generally not possible for RP-TFA. A daily intake of $5 \mathrm{~g}$ TFA (primarily IPTFA) is associated with a $29 \%$ increased risk of coronary heart disease. Such an association is not found for RP-TFA up to a daily intake of $4 \mathrm{~g}$.

The high amount of IP-TFA in popular foods, the evidence of a more harmful effect on health by IP-TFA than by RP-TFA, and the feasibility of eliminating IP-TFA from foods without side effects for the population, suggest that a selective elimination of IP-TFA from our food is a 'low hanging fruit' in the quest for a more healthy diet for subgroups of the population.

Keywords: trans fatty acids; ruminant; industrial; hydrogenated fats; health aspects; cardio-vascular disorders; obesity

I ndustrially produced trans fatty acids (IP-TFA) are made by partial hydrogenation of vegetable fat, and to a lesser extent, of fish oils by heating to about $400^{\circ} \mathrm{C}$ under high pressure and with the addition of different catalysts. IP-TFA is used in a variety of food products, especially margarines, spreads, baked goods, and fast food. Ruminant-produced trans fatty acids (RPTFA) are made by bacterial metabolism of polyunsaturated fatty acids in the rumen of ruminants, such as cow, sheep and goat, and are consequently present in all fats from these animals. The concentration of IP-TFA in partially hydrogenated fat may be as high as $60 \%$, whereas the maximum content of RP-TFA in ruminant fat is about $6 \%$. In milk, RP-TFA is $4-6 \%$ of the fat. The average distribution of RP-TFA intake in Denmark is $85 \%$ from dairy products and $15 \%$ from ruminant meat (1). Consequently, the intake of RP-TFA is mainly determined by the intake of high-fat dairy products.

During industrial hydrogenation, trans double bonds are formed along the fatty acid molecules from position 6 and higher. For fatty acids with 18 carbon atoms, a peak concentration of trans double bonds is found in position 9, as elaidic acid, with a Gaussian distribution of fatty acids with the trans bond in the other positions. The bacterial desaturation of polyunsaturated fat from grass and vegetables in the rumen also produces trans double bonds all over the fatty acid molecules, but with a distinct preference for the double bond in position 11 of the 18 carbon fatty acids, as vaccenic acid (Fig. 1). Low amounts of trans fatty acids from linoleic and linolenic acids together with trans fatty acids with 16, 20, and 22 carbon atoms, etc., are also formed both industrially and in the rumen. Thus, ruminant fat may contain up to $20 \%$ of its trans fatty acids as 16:1, which does not occur in IPTFA from vegetable oils. This fatty acid together with butyric acid may therefore be used as markers for RPTFA in a mixture of RP-TFA and IP-TFA of vegetable origin. However, hydrogenated marine oils can contain trans 16:1. Trans $18: 1$ contributes $80-90 \%$ of total trans fatty acids in human food. There is a considerable overlap of trans fatty acids in IP-TFA and RP-TFA (2) (Fig. 1). 


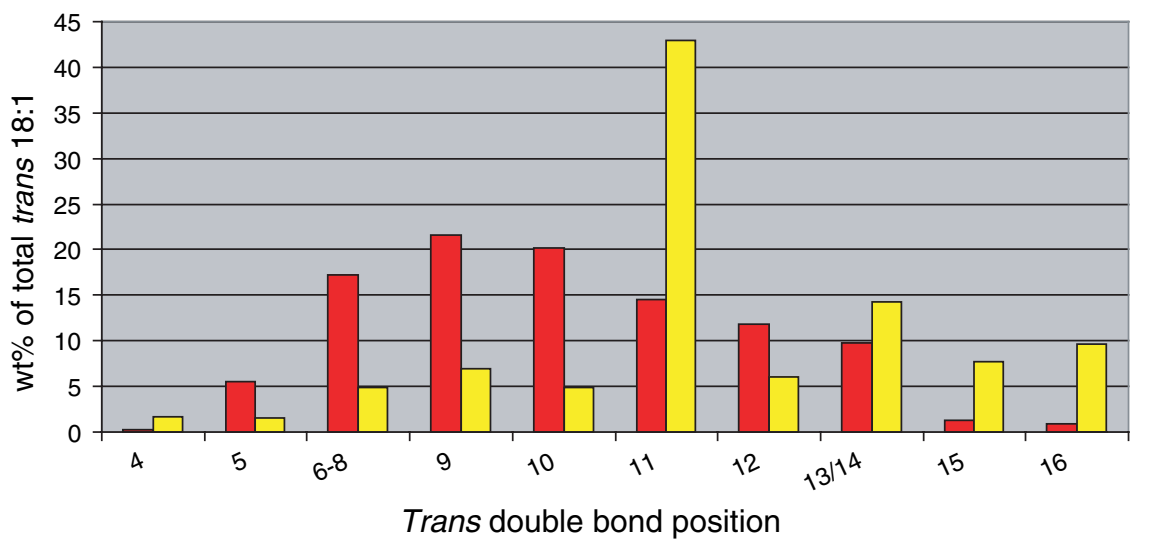

Industrially produced trans fatty acids (IP-TFA)

Ruminant trans fatty acids (RP-TFA)

Fig. 1. Isomeric distribution of trans-octadecenoic acids in industrially produced and ruminant trans fat (mean wt $\%$ of trans-18:1 fatty acids) adapted from Wolff et al. (2).

\section{Intake of trans fatty acids}

Estimates of the intake of trans fatty acids usually rely on estimates of food consumption and the use of appropriate food composition tables. The estimates of food consumption need to be detailed since the content of IP-TFA in apparently similar foods may vary considerably in the same country and from time to time. We found that a serving of fast food in Hungary in 2006 contained $24 \mathrm{~g}$ of IP-TFA in one fast-food chain, whereas a similar serving contained $<5 \mathrm{~g}$ when bought at another fast food chain in the same city. Even when bought at the same chain in the same country, trans fat content may vary in apparently identical servings, for instance in Germany, where we found $5 \mathrm{~g}$ in Hamburg, and $0.5 \mathrm{~g}$ in Wiesbaden (3). The amount of IP-TFA in the same brand of food may also vary from time to time, depending on market prices for edible fats, and on the willingness of the individual food producer to comply with societal pressure for reducing the content of IP-TFA in the food.

Concentrations of RP-TFA in ruminant fat varies with the feed of the animals and therefore with the seasons (1). This variation in gram per serving is, however, much lower than the variation observed for IP-TFA.

As a consequence, estimates of trans fatty acid intake should be interpreted with great caution and preferably be supported by analysis of duplicate portions or composite diets, together with measurements of biomarkers for intake, such as trans fatty acid in human tissue, including plasma, erythrocytes, subcutaneous fat, and human milk.

The total intake of trans fatty acids in various European countries has been investigated in the 'Transfair Study', conducted in 1996 (4). The average daily intakes varied from $5.4 \mathrm{~g}$ in Iceland to about $1.5 \mathrm{~g}$ in Greece and Italy. In Sweden and Denmark, the intake of total TFA was approximately $2.5 \mathrm{~g}$, in Finland about $2.0 \mathrm{~g}$, and in Norway about $4.0 \mathrm{~g}$. In general, the 90 th percentiles were $50-70 \%$ above the mean values. In the US, the mean intake of trans fatty acids has been estimated to be $5.3 \mathrm{~g} /$ day, with the 90 th percentile at $9.4 \mathrm{~g} /$ day (5).

The intake of RP-TFA in Denmark in 1996 has been investigated in detail (1). A total of 3,098 persons were asked to complete a 7-day food diary, and the intake of RP-TFA was calculated for the population, aged 1-80 years, based on food composition tables. The mean intake was $1.2 \mathrm{~g} / \mathrm{day}$, the median intake $1.7 \mathrm{~g}$, the 90th percentile $2.9 \mathrm{~g}$, and the 99 th percentile $4.4 \mathrm{~g}$.

Since 1996, the intake of IP-TFA has decreased considerably in Denmark as well as in other countries in Western Europe, including Scandinavia, due to societal pressure on food producers to reduce the content of IPTFA (Fig. 2A). The steep decline in Denmark between 1990 and 1996 may be ascribed to the effect of the first report by The Danish Nutrition Council in 1994 on trans fat and human health (6). Producers of table margarine were especially responsive to pressure and removed nearly all IP-TFA from table margarines (7). In Denmark, the amount of milk fat and ruminant meat available for consumption has been relatively constant from 1970 to 2001 (8). Therefore, it seems likely that the intake of RPTFA in 2007 is similar to the intake in 1996 (Fig. 2A). This is probably also the case for the intake of RP-TFA in the other Scandinavian countries.

Although the mean intake of IP-TFA in Denmark in 1996 was only about $1 \mathrm{~g} /$ day, a wide distribution of IPTFA in some popular foods made it possible for some 

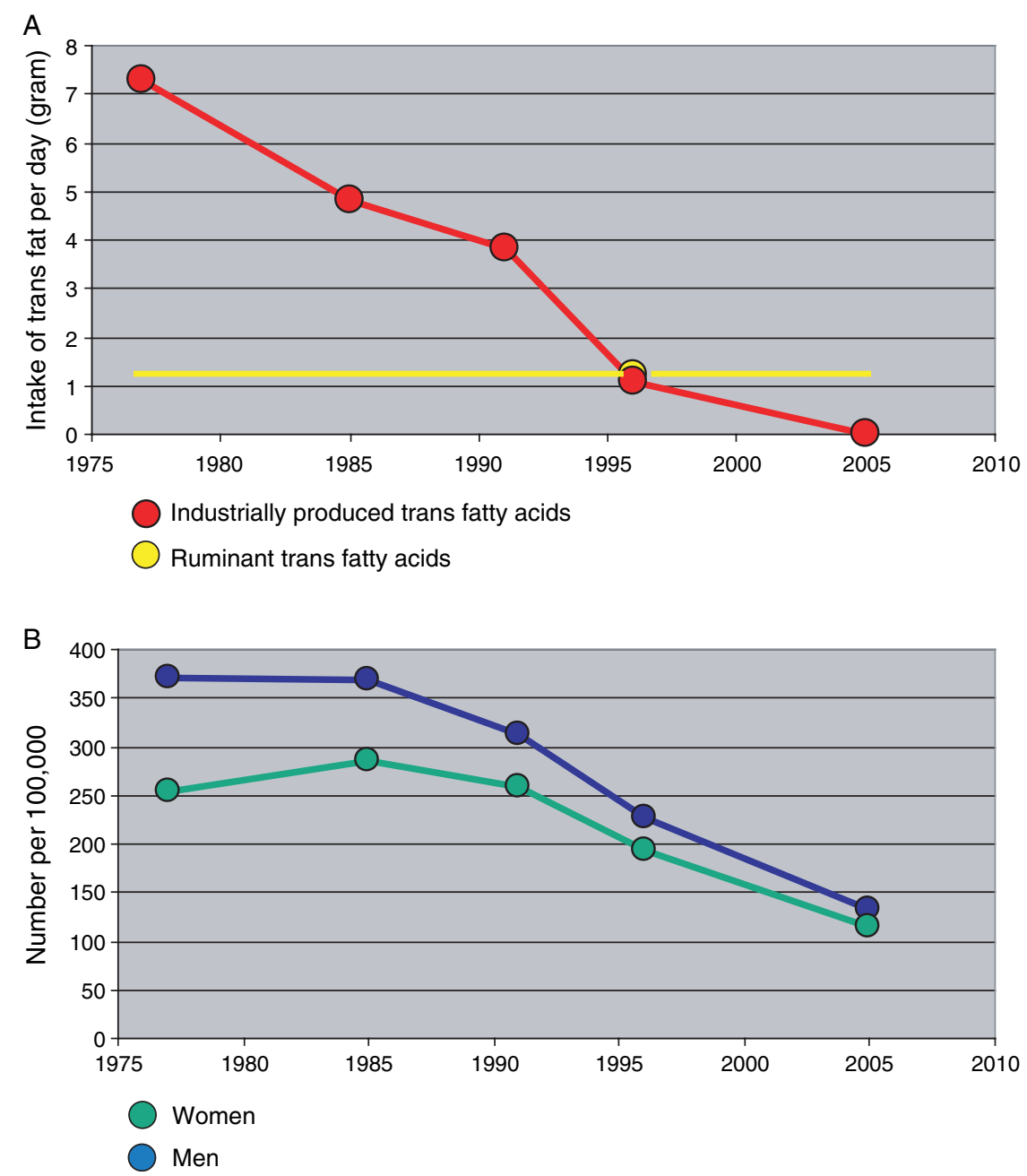

Fig. 2. (A) The average intake of industrially produced and ruminant trans fatty acids in Denmark from 1978 to 2005 . The intake of ruminant fat was measured in 1996 (1). Some studies suggest that this intake has been constant from 1972 to 2005. (B) Mortality curves for coronary heart disease in Denmark during the period with decreasing intake of industrially produced trans fatty acids, but constant intake of ruminant trans fatty acids.

people to consume much more. A high intake of IP-TFA in a minority of the population concerned the Danish Nutrition Council who conducted a survey in 2001 and found that a number of popular food items contained fat with up to $60 \%$ IP-TFA (9). The popular food items consisted of fast food meals (fried meat and French fries), microwave oven popcorn, and a variety of biscuits and wafers. In Denmark in 2001 it was thus possible to have a high trans fat menu with about $30 \mathrm{~g}$ of IP-TFA, and about $1 \%$ of the 5.6 million Danes were estimated to have a daily intake of $>5 \mathrm{~g} /$ day. This situation prompted the Danish parliament to pass legislation in 2003 making it illegal to use fat with $>2 \%$ IP-TFA, whether the food was produced in Denmark or imported $(10,11)$. After a few years, the intake of IP-TFA was virtually eliminated in Denmark, without any nutritional or economic side effects. Initially, the legislation was challenged by the EU Commission, but was endorsed by the Commission in
2007 due to 'increased scientific evidences on the dangers of trans fat'. Similar legislation has now been introduced for food sold in the 20,000 restaurants in New York City.

In a series of countries, from 2005 to 2007 we investigated the extent to which it was possible to obtain a high intake of IP-TFA (12). The results are shown in Fig. 3. It is noteworthy that a menu with a high IP-TFA content could not be obtained in Denmark in 2005. In contrast, the existence of popular foods with high amounts of IPTFA in the various other countries suggests that certain groups within these populations daily consume $5 \mathrm{~g}$ of IPTFA or more. These groups might represent $<1 \%$ of the total population, however in the EU with a population of 500 million, they may still constitute 5 million people. The majority of people in the EU exposed to a high intake of IP-TFA live in Eastern Europe.

The possibility of consuming higher amounts of IPTFA compared to RP-TFA is exemplified in Fig. 4 by the 


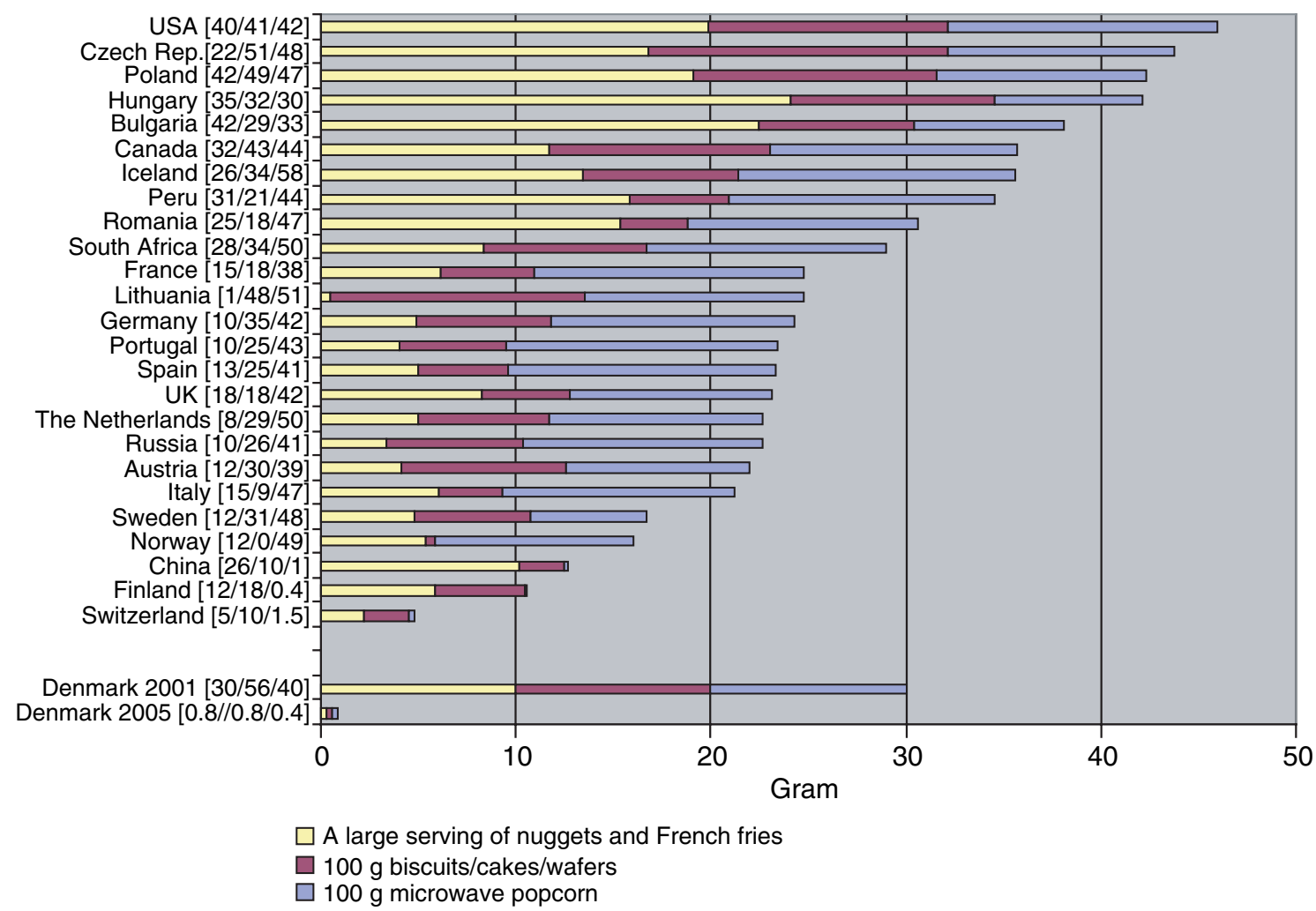

Fig. 3. Grams of industrially produced trans fatty acids in a 'high trans fat menu'. A large serving of fast food consists of $160 \mathrm{~g}$ of nuggets and $171 \mathrm{~g}$ of French fries. In each country, the products with the highest amount of trans fatty acids per $100 \mathrm{~g}$ product in each category are shown. Values in brackets are percent trans fatty acids of total fat in French fries, biscuits/cakes/wafers and microwave oven popcorn, respectively. The foods were bought between 2005 and 2008 .

differing amounts of trans fatty acids in ruminant meat compared to a similar sized portion of a deep fat fried chicken meat product from the same fast food chain, fried in oils with a high IP-TFA content (3).

\section{Intake of IP-TFA and RP-TFA and heart disease}

The results from observational studies concerning the intake of TFA and coronary heart disease (CHD) demonstrate that the intake of RP-TFA has either not

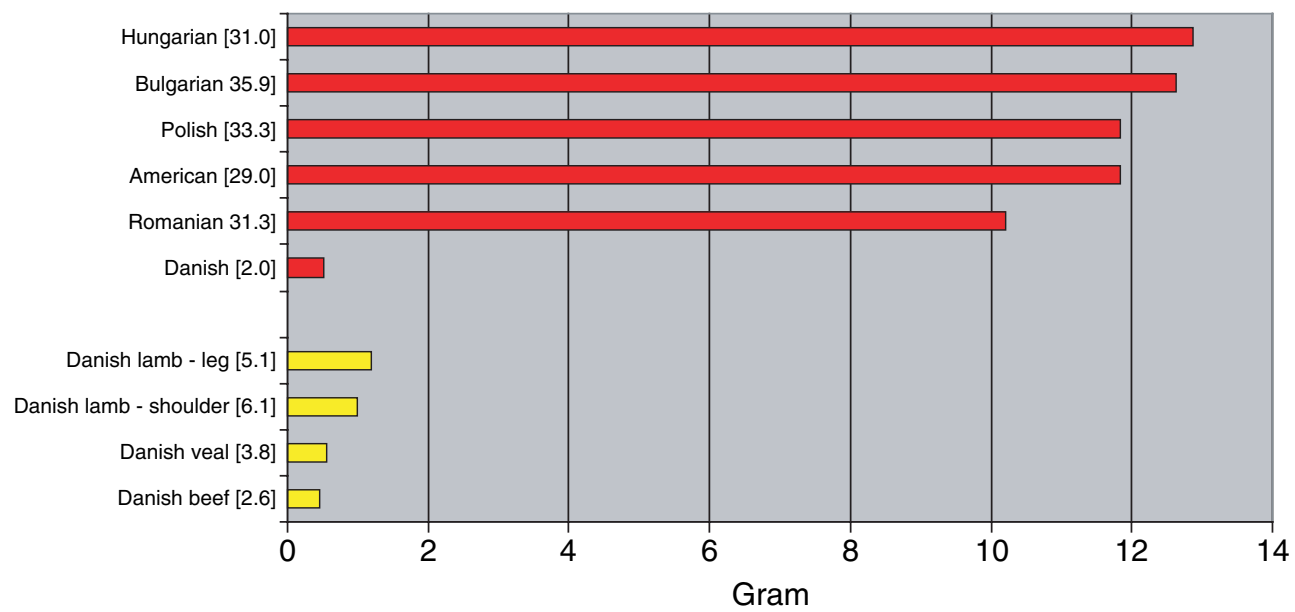

Industrially produced trans fatty acids (IP-TFA) in a deep fat fried chicken meat product Ruminant transfatty acids (RP-TFA)

Fig. 4. Trans fatty acids in $160 \mathrm{~g}$ meat from two different sources. Values in brackets are percent trans fatty acids of total fat. 
Table 1. Characteristics of observational studies on intake of ruminant and industrial trans fatty acids and risk of coronary heart disease

\begin{tabular}{|c|c|c|c|c|c|c|c|}
\hline \multirow[b]{2}{*}{ Study name (reference) } & \multirow[b]{2}{*}{$\begin{array}{l}\text { No. of } \\
\text { subjects }\end{array}$} & \multirow[b]{2}{*}{$\begin{array}{l}\text { No. of } \\
\text { cases }\end{array}$} & \multirow[b]{2}{*}{$\begin{array}{l}\text { Definition of } \\
\text { end points }\end{array}$} & \multicolumn{2}{|c|}{ TFA intake (g/day) } & \multicolumn{2}{|c|}{ Relative risk of CHD } \\
\hline & & & & Industrial & Ruminant & Industrial & Ruminant \\
\hline \multicolumn{8}{|l|}{ Prospective cohort studies } \\
\hline Nurses' Health Study (I3) & $85,095 \mathrm{~W}$ & 431 & $\begin{array}{l}\text { Non-fatal MI or } \\
\text { coronary death }\end{array}$ & $1.44-3.42$ & $0.96-2.28$ & $1.78(p=0.009)^{*}$ & $0.59(p=0.23)^{*}$ \\
\hline ATBC Study (14) & $21,930 \mathrm{M}$ & 635 & Coronary death & $0.1-5.1$ & $0.6-2.5$ & $1.23(p=0.004)^{*}$ & $0.83(p=0.0035)^{*}$ \\
\hline Zutphen Cohort Study (I5) & $667 \mathrm{M}$ & 98 & Fatal and non-fatal MI & 5.0 & 1.7 & 1.05 & 1.17 \\
\hline Danish ruminant trans fatty & I,866 M & 253 & Fatal and non-fatal MI & - & $0.6-4.1$ & - & $1.00(0.91-1.07)$ \\
\hline acid study (16) & I,91। W & 121 & Fatal and non-fatal MI & - & $0.5-3.1$ & - & $0.84(0.70-1.01)$ \\
\hline \multicolumn{8}{|l|}{ Case-control studies } \\
\hline Ascherio et al. (17) & $407 \mathrm{M} ; \mathrm{II} 4 \mathrm{~W}$ & 239 & MI & $0.84-5.04$ & $0.45-1.79$ & $\mathrm{I} .94(p=0.000 \mathrm{I})^{*}$ & $1.02(p=0.57)^{*}$ \\
\hline
\end{tabular}

Adapted from Weggemans et al. (19).

$\mathrm{MI}=$ myocardial infarction, $\mathrm{CHD}=$ coronary heart disease, $\mathrm{W}=$ women. $\mathrm{M}=$ men.

* $p$ for trend.

been associated with or has been negatively associated with the risk of CHD (Table 1). By contrast, the intake of IP-TFA has consistently shown a positive association with the risk of CHD (19).

Table 1 also shows that the average daily intake of IPTFA in these studies is considerably larger than that from ruminant sources. In the Danish study, the average daily intake of RP-TFA is higher than the 0.5-2.5 $\mathrm{g}$ in the other studies in Table 1. The Danish study did not find any positive association between intakes of RP-TFA and the risk of $\mathrm{CHD}$, when the risk was adjusted for the intake of saturated fat. The intake of IP-TFA as a dietary risk factor for CHD was adjusted for by taking into account the weighted intake of foods containing high amounts of IP-TFA. The RP-TFA intake of up to $4 \mathrm{~g}$ /day had a slightly negative association with $\mathrm{CHD}$ in females, whereas there was no association in males (Fig. 5). These results are consistent with the findings on RP-TFA intake in the Nurses Health Study and the Finnish ATBC study $(13,14)$; the intake of RP-TFA approaches the intake of IP-TFA in these studies (Table 1). Taken together, the findings support the hypothesis that RP-TFA intake does not increase the risk for CHD, and that IP-TFA is more harmful than RP-TFA when compared on a gramto-gram basis. Therefore, the findings contradict the suggestion that, at equal amounts of intake, IP-TFA
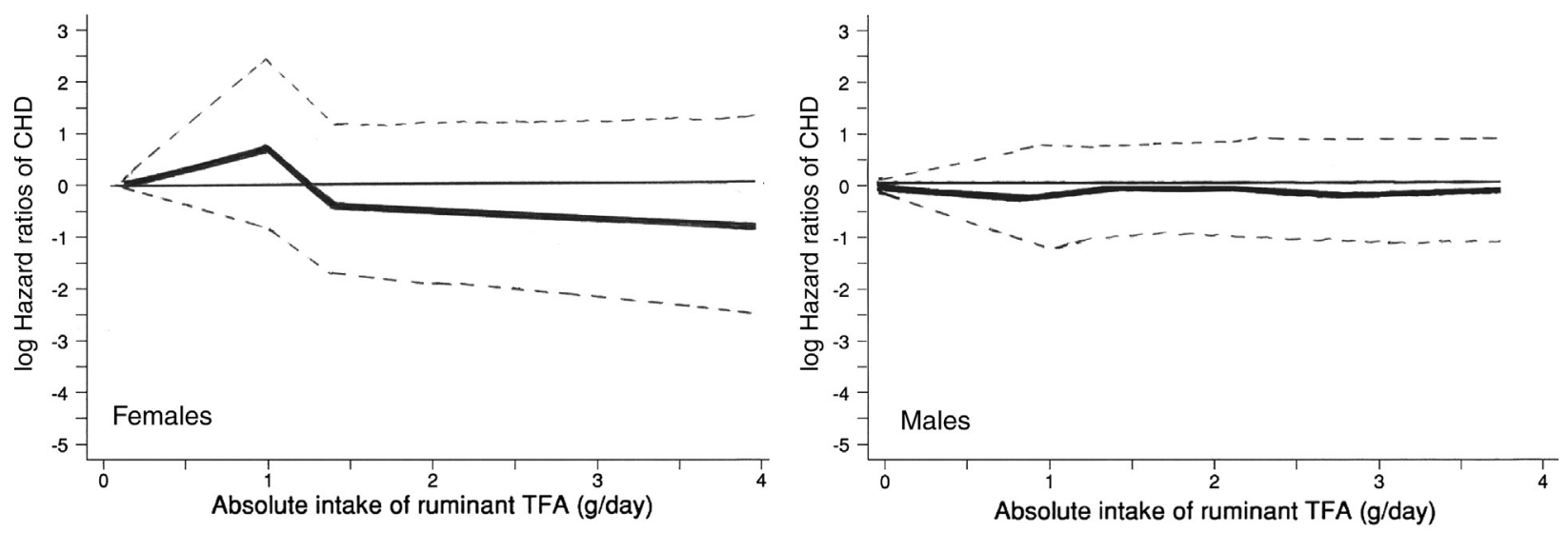

Solid line: point estimates

Dashed lines: 95 percent confidence

Fig. 5. Spline regression analysis of the log hazard ratios of coronary heart disease according to intake of ruminant trans fatty acid (RP-TFA) in an 18-year prospective study ending in 2000 of 3,686 Danish women and men aged 30-71 years. Adapted from Jakobsen et al. (16). 
and RP-TFA are associated with similar risks for CHD (19).

In a prospective, nested, case control study of trans fatty acids in erythrocytes, an objective marker of dietary intake of trans fatty acids, it was observed that higher total trans fatty acid content was associated with an elevated risk of CHD (20). For 18:1 trans isomers, CHD cases had significantly higher contents $(p<0.001$ and $<$ 0.01 , respectively) of 18:1 n-12 and 18:1 n-9 (elaidic acid) than controls. For vaccenic acid (18:1 n-7), the difference did not reach statistical significance $(p=0.05)$.

\section{Other epidemiological studies}

Death due to CHD in Denmark (and in other countries in the western hemisphere) has declined since 1980. This reduction coincides with the reduction in IP-TFA intake during a period of unchanged RP-TFA consumption (Fig. 2A,B). The reduction in CHD has been explained by a favorable change in a number of traditional risk factors, such as smoking, hypercholesterolemia and hypertension. On the other hand, physical inactivity and obesity rates have increased. We hypothesize that the decline in the intake of IP-TFA also plays a beneficial role in the reduction.

Iceland and Norway have previously had a high intake of IP-TFA compared with the other Nordic countries, but did not have a correspondingly higher incidence of CHD. In both Iceland and Norway, the intake of omega- 3 fatty acids from fish and cod liver oil has been considerably higher than in the other Nordic countries. This intake of fish oil may have counteracted the harmful effect of greater IP-TFA intake, according to the Yin-Yang hypothesis for the effect on human health of these two types of fatty acids (22)

\section{Suggestion for a new study of the effect of RP-TFA} Observational studies with RP-TFA are few compared with the same type of studies with IP-TFA. Furthermore, observational studies on the association between health and RP-TFA intake are difficult to interpret because one must adjust first, for the effect of the much larger amounts of saturated fatty acids in dairy products and meat, which varies in proportion with the content of RPTFA, and second, for the effects of fatty acids from other sources, such as omega-3 fatty acids and IP-TFA. Adjusting for the intake of the latter would not be necessary in Denmark, where the intake of IP-TFA has virtually been eliminated. Since Denmark has a wide distribution of intake of RP-TFA it may be possible to shed more light on the RP-TFA/CHD association by conducting an observational study on the Danish population, commencing with intake data after 2003, when enforcement of the legislative ban on IP-TFA went into effect.
Mechanisms of harmful effects of trans fatty acids In many intervention studies, IP-TFA intake has been shown to result in lower HDL and higher LDL concentrations in plasma compared with intake of saturated fat. Whether this is the case at low intakes of IP-TFA has been challenged. Most studies suggest a linearity of this effect on plasma lipids, meaning that a gram-for-gram replacement of IP-TFA with saturated fat results in a more beneficial LDL/HDL ratio acid study (21).

The unfavorable change in blood lipids accounts, however, for only a fraction of the harmful effect of trans fatty acids found in observational studies (18). The remaining effect might be due to the effects of trans fatty acids beyond those exerted on plasma lipids. It has been suggested that pro-inflammatory and pro-arrhythmogenic actions occur (23). Except for the impact of IPTFA on plasma lipoproteins, the effect on other risk markers of CHD has not been reproducibly demonstrated in intervention studies (24).

In a study with male hamsters fed diets enriched with fatty acids for 4 weeks, it was observed that when elaidic and vaccenic acid were compared, the ratio of LDL/ HDL-cholesterol in plasma was significantly higher in hamsters fed vaccenic acid (25).

To date, the effect of RP-TFA on plasma lipid and lipoprotein risk-markers of CHD has been investigated in only one human, randomized, cross-over study in 22 males and 24 females, fed either 11-12 g/day of RP-TFA or IP-TFA for 3 weeks, with a 1-week wash-out period in between. There was apparently no difference in the effect of RP-TFA on LDL or HDL concentration compared with the effect of IP-TFA in males, whereas both LDL and HDL were significantly higher after RP-TFA in females (26).

Unlike elaidic acid from IP-TFA, vaccenic acid from either IP-TFA or RP-TFA can be converted to rumenic acid, most notably by ruminant animals, but also in nonruminant animals as well as in humans. Rumenic acid is a so-called conjugated linoleic acid (CLA) which may have positive metabolic effects, although the results in humans have been contradictory. It is noteworthy that a high intake of IP-TFA may provide more vaccenic acid than an average intake of RP-TFA. If vaccenic acid has a beneficial effect on coronary risk, this must be more than counteracted by the harmful effect of the other IP-TFA to explain the negative association between the intake of IP-TFA and coronary risk.

\section{Harmful effect of TFA on fetal development}

There are biochemical reasons to believe that IP-TFA and RP-TFA compete with long chain fatty acids during their incorporation in the developing brain. The observational evidence for a harmful effect of IP-TFA on the development of the fetus and newborn is weak. The possibility of avoiding the introduction of a new type of fatty acid in 
the brain early in life, however, seems preferable. It should be noted, though, that a high intake of RP-TFA by the newborn in infant formulas based on cow milk may also be considered as a new type of fatty acid in the diet compared with the fatty acids from mother's milk.

\section{Randomized studies with hard end points}

Due to ethical concerns, we will probably never see randomized studies in humans with hard end points, such as coronary events or death, concerning the health effects of IP-TFA and RP-TFA.

In a study of 32 male green monkeys given a diet with a high content of IP-TFA fat compared with a diet in which IP-TFA was replaced by oleic acid for 6 years, the IP-TFA intake promoted abdominal fat deposition and increased postprandial insulin levels in plasma (27). This study thus suggests that IP-TFA may interfere with biological processes in the body other than those directly linked to the development of CHD, even if caution should be exerted in extrapolation from monkeys to man. However, the observational epidemiology also supports the association between IP-TFA intake and abdominal obesity (28).

If an obesity promoting effect of IP-TFA is making a contribution to the current obesity epidemic, one would assume that obesity prevalence in Denmark might be related to the rapid decline and elimination of IP-TFA over the last 20 years. This is indeed the case. Results from the Danish Army draft boards, which is mandatory and where height and weight are measured, clearly demonstrate that the increasing obesity rates seem to have leveled off (Fig. 6).

\section{Summary of evidence}

Intake of IP-TFA is associated with the occurrence of CHD, and there are some plausible mechanisms to explain at least some of this association.
For RP-TFA intake, no association with increased CHD has been found. By contrast, even negative associations have been seen in some studies after adjustment for the simultaneous intake of saturated fat.

For both IP-TFA and RP-TFA there is a lack of randomized intervention studies with hard end points. Such studies could be helpful in establishing the extent to which intake of these fatty acids affect human health. However, intervention studies will probably never be carried out because it is unethical to verify suspicions of harmful effects when the suspected exposure can be removed without negative effects on health.

In the opinion of the authors, the strong suspicion of a harmful effect of IP-TFA intake, even more harmful than that of saturated fats, and the possibility of removing IPTFA from food, places the burden of proving that IPTFA in human foods is safe on those who would like to add IP-TFA to our food supply.

On the other hand, the lack of evidence for a harmful effect of RP-TFA intake, and the fact that these fatty acids cannot be removed from ruminant fat and have been part of human food in millennia, places the burden of proving that these fats are more harmful than saturated fats on those who would like to reduce the intake of RP-TFA beyond levels produced by a reduction in saturated fats generally.

\section{Conclusion}

The intake of ruminant trans fatty acids is maximally 4-5 $\mathrm{g} /$ day, whereas the intake of industrially produced trans fat in some population groups far exceeds $5 \mathrm{~g} /$ day. Since there is evidence for harmful effects of industrially produced trans fatty acids at this level, but not for ruminant trans fatty acids, and since it is feasible to eliminate industrially produced trans fatty acids from the food supply without side effects in the population, this elimination can be considered a 'low hanging fruit' in the

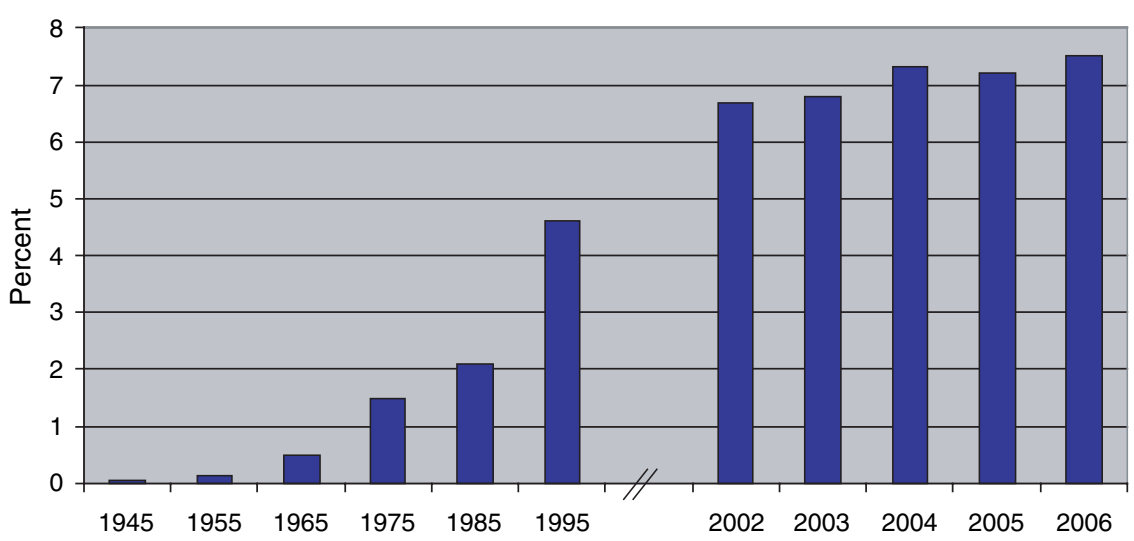

Fig. 6. Prevalence of obesity among young Danish males attending mandatory draft boards ( $\%$ with BMI $\left.>20 \mathrm{~kg} / \mathrm{m}^{2}\right)$. Data up to 2000 were modified from Sorensen and Price (29) and Sørensen et al. (30), data after 2000 were kindly provided by the Danish Ministry of Interior and Health. 
quest for a more healthy diet for the entire population in any given country. How to do it is a political issue.

\section{Conflict of interest and funding}

The paper is based on a presentation at a conference on health aspects of milk fat, 30-31 August 2007, Stockholm, Sweden, arranged by the Swedish Dairy Association, who also sponsored the fee due to the publication of this article. Arne Astrup is a member of Global Dairy Platform, Chicago and a member of Arla Amba Nutrition Advisory Board.

\section{References}

1. Jakobsen MU, Bysted A, Andersen NL, Heitmann BL, Hartkopp HB, Leth T, et al. Intake of ruminant trans fatty acids in the Danish population aged 1-80 years. Eur J Clin Nutr 2006; 60(3): 312-8.

2. Wolff RL, Precht D, Molkentin J. Occurrence and distribution profiles of trans-18:1 acids in edible fats of natural origin. In: Sebedio JL, Christie WW, eds. Trans fatty acids in human nutrition. Dundee, UK: The Oily Press; 1998, pp. 1-33.

3. Stender S, Dyerberg J, Astrup A. High levels of industrially produced trans fat in popular fast foods. N Engl J Med 2006; 354: $1650-2$.

4. Hulshof KF, van Erp-Baart MA, Anttolainen M, Becker W, Church SM, Couet C, et al. Intake of fatty acids in western Europe with emphasis on trans fatty acids: the TRANSFAIR Study. Eur J Clin Nutr 1999; 53(2): 143-57.

5. Allison DB, Egan SK, Barraj LM, Caughman C, Infante M, Heimbach JT. Estimated intakes of trans fatty and other fatty acids in the US population. J Am Diet Assoc 1999; 99(2): $166-74$.

6. Stender S, Dyerberg J, Hølmer G, Ovesen L, Sandstrøm B. Transfedtsyrers betydning for sundheden. A report from the Danish Nutrition Council, Publication No 2. Copenhagen; 1994.

7. Leth T. Bysted A, Hansen K, Ovesen L. Trans fat content in Danish margarines and shortenings marketed in Denmark. JAOCS 1998; 75: 1079-83.

8. Fagt S, Trolle E. Forsyning af fødevarer 1955-1999. Udvikling i danskernes kost-forbrug, indkøb og vaner. National Food Agency of Denmark, Søborg (in Danish); 2001.

9. Stender S, Dyerberg J. Transfedtsyrers betydning for sundheden. Opdatering år 2001 A report from the Danish Nutrition Council, Publication No 23. Copenhagen; 2001.

10. Stender S, Dyerberg J. The influence of trans fatty acids on health (4th edn.) A report from the Danish Nutrition Council. Publication No 34, Copenhagen; 2003.

11. Stender S, Dyerberg J, Astrup A. Consumer protection through a legislative ban on industrially produced trans fatty acids in foods in Denmark. Scand J Food Nutr 2006; 50(4): 155-60.

12. Stender S, Dyerberg J, Bysted A, Leth T, Astrup A. A trans world journey. Atheroscler Suppl 2006; 7(2): 47-52.

13. Oh K, Hu FB, Manson JE, Stampfer MJ, Willett WC. Dietary fat intake and risk of coronary heart disease in women: 20 years of follow-up of the nurses' health study. Am J Epidemiol 2005; 161(7): 672-9.

14. Pietinen P, Ascherio A, Korhonen P, Hartman AM, Willett WC, Albanes D, et al. Intake of fatty acids and risk of coronary heart disease in a cohort of Finnish men. The Alpha-Tocopherol, Beta-Carotene Cancer Prevention Study. Am J Epidemiol 1997; 145(10): 876-87.
15. Oomen CM, Ocké MC, Feskens EJ, van Erp-Baart MA, Kok FJ, Kromhout D. Association between trans fatty acid intake and 10-year risk of coronary heart disease in the Zutphen Elderly Study: a prospective population-based study. Lancet 2001; 357(9258): 746-51.

16. Jakobsen MU, Overvad K, Dyerberg J, Heitmann BL. Intake of ruminant trans fatty acids and risk of coronary heart disease. Int J Epidemiol 2008; 37(1): 173-82.

17. Ascherio A, Rimm EB, Giovannucci EL, Spiegelman D, Stampfer M, Willett WC. Dietary fat and risk of coronary heart disease in men: cohort follow up study in the United States. BMJ 1996; 313(7049): 84-90.

18. Mozaffarian D, Katan MB, Ascherio A, Stampfer MJ, Willett WC. Trans fatty acids and cardiovascular disease. N Engl J Med 2006; 354(15): 1601-13.

19. Weggemans RM, Rudrum M, Trautwein EA. Intake of ruminant versus industrial trans fatty acids and risk of coronary heart disease - what is the evidence? Eur J Lipid Sci Technol 2004; 106: 390-7.

20. Sun Q, Ma J, Campos H, Hankinson SE, Manson JE, Stampfer $\mathrm{MJ}$, et al. A prospective study of trans fatty acids in erythrocytes and risk of coronary heart disease. Circulation 2007; 115: 1858-65.

21. Ascherio A, Katan MB, Zock PL, Stampfer MJ, Willett WC. Trans fatty acids and coronary heart disease. N Engl J Med 1999; 340(25): 1994-8.

22. Dyerberg J, Christensen JH, Eskesen D, Astrup A, Stender S. Trans, and n-3 polyunsaturated fatty acids and vascular function - a yin yang situation. Atheroscler Suppl 2006; 7(2): 33-35.

23. Mozaffarian D. Trans fatty acids - effects on systemic inflammation and endothelial function. Atheroscler Suppl 2006; 7(2): 29-32.

24. Dyerberg J, Eskesen DC, Andersen PW, Astrup A, Buemann B, Christensen JH, et al. Effects of trans and n-3 unsaturated fatty acids on cardiovascular risk markers in healthy males. An 8 weeks dietary intervention study. Eur J Clin Nutr 2004; 58: 1062-70.

25. Meijer GW, van Tol A, van Berkel TJC, Weststrate JA. Effect of dietary elaidic versus vaccenic acid on blood and liver lipids in the hamster. Atherosclerosis 2001; 157: 31-40.

26. Chardigny JM, Malpuech-Brugère $\mathrm{C}$, Dionisi $\mathrm{F}$, Bauman DE, German B, Mensink RP, et al. Rationale and design of the TRANSFACT project phase I: a study to assess the effect of the two different dietary sources of trans fatty acids on cardiovascular risk factors in humans. Contemp Clin Trials 2006; 27(4): 364-73.

27. Kavanagh K, Jones KL, Sawyer J, Kelley K, Carr JJ, Wagner JD, et al. Trans fat diet induces abdominal obesity and changes in insulin sensitivity in monkeys. Obesity 2007 ; 15 : 1675-84.

28. Stender S, Dyerberg J, Astrup A. Fast food: unfriendly and unhealthy. Int J Obes 2007; 31(6): 887-90.

29. Sorensen TI, Price RA. Secular trends in body mass index among Danish young men. Int J Obes 1990; 14(5): 411-9.

30. Sørensen HT, Sabroe S, Gillman M, Rothman KJ, Madsen KM, Fischer P, et al. Continued increase in prevalence of obesity in Danish young men. Int J Obes Relat Metab Disord 1997; 21(8): $712-4$.

\section{Steen Stender}

Department of Clinical Biochemistry, Gentofte University Hospital,

Niels Andersens Vej 65, opg. 38, 2900 Hellerup, Denmark

Phone: +45-3977-3120;

Fax: +45-3997-8193;

E-mail: stst@geh.regionh.dk 